
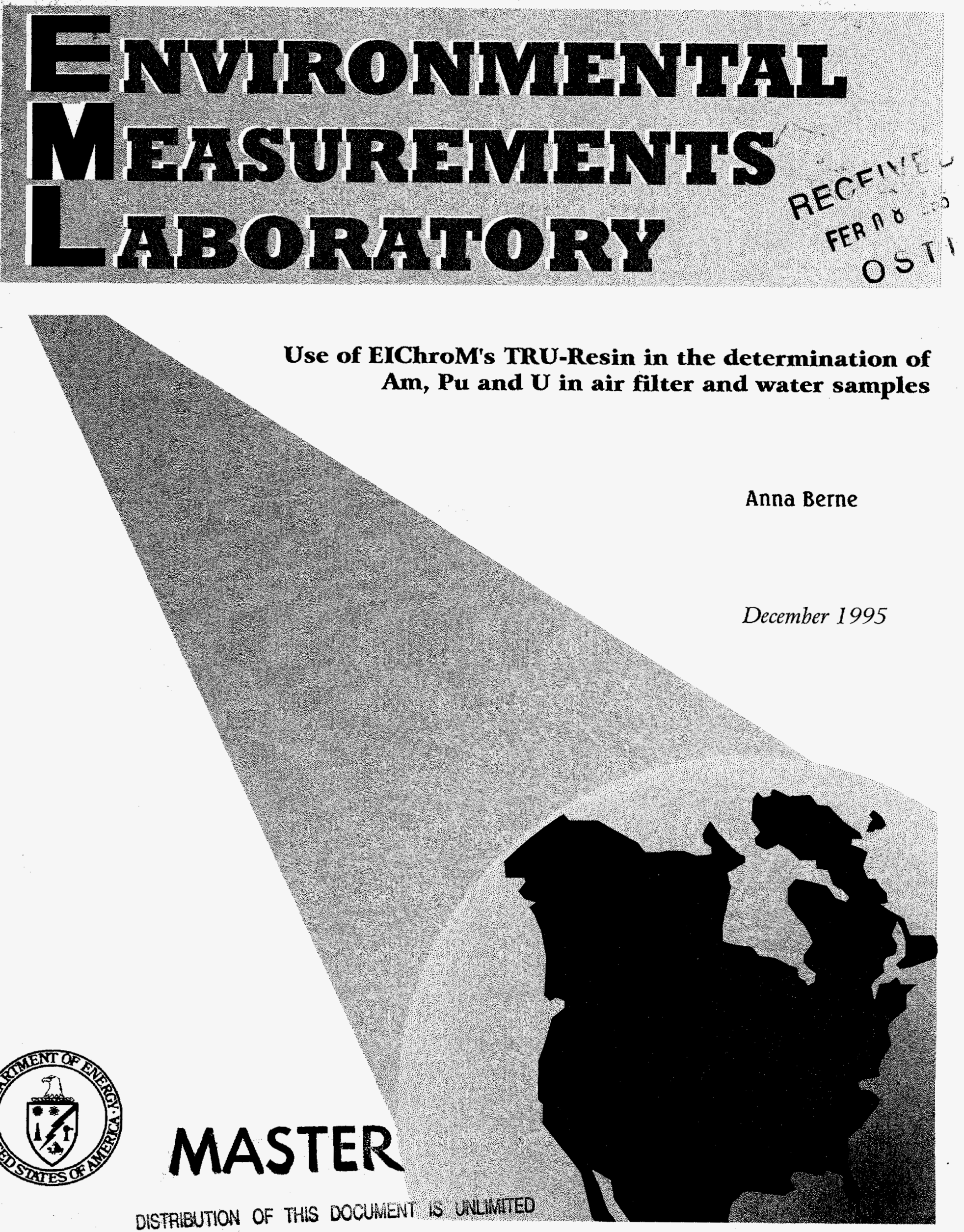


\title{
USE OF EICHROM'S TRU RESIN IN THE DETERMINATION OF AMERICIUM, PLUTONIUM AND URANIUM IN AIR FILTER AND WATER SAMPLES
}

\author{
Anna Berne \\ Environmental Measurements Laboratory \\ U. S. Department of Energy \\ New York, NY 10014-3621
}

December 1995

\section{DISCLAIMER}

"This report was prepared as an account of work sponsored by an agency of the United States Government. Neither the United States Government nor any agency thereof, nor any of their employees, makes any warranty, express or implied, or assumes any legal liability or responsibility for the accuracy, completeness, or usefulness of any information, apparatus, product, or process disclosed, or represents that its use would not infringe privately owned rights. Reference herein to any specific commercial product, process, or service by trade name, trademark, manufacturer, or otherwise, does not necessarily constitute or imply its endorsement, recommendation, or favoring by the United States Government or any agency thereof. The views and opinions of authors expressed herein do not necessarily state or reflect those of the United States Government or any agency thereof."

This report has been reproduced directly from the best available copy.

Available from the National Technical Information Service, U.S. Department of Commerce, 5285 Port Royal Road, Springfield, Virginia 22161. 


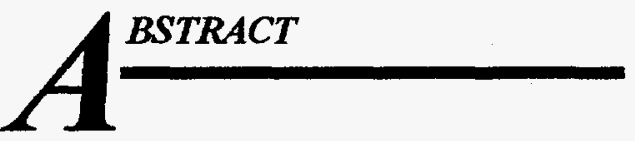

TRU Resin, an extraction chromatographic material ((octyl (phenyl)-N,Ndiisobutylcarbamoylmethylphosphene oxide (CMPO) dissolved in tributyl phosphate (TBP)) manufactured by EIChroM Industries, was tested for its actinide sorption and desorption characteristics. A study was initiated to demonstrate the effectiveness of extracting plutonium, americium and uranium from water and air filter samples from the Environmental Measurements Laboratory's Quality Assessment Program (QAP), and the effectiveness of subsequent desorption of one chemical species at a time in order to prepare each of them for $\alpha$ spectrometry. Crossover of plutonium into the americium fraction with the TRU Resin was observed and could not be eliminated while using TRU Resin only. However, prior extraction of plutonium using an anion exchange resin can overcome this problem. A method for the determination of americium is proposed which combines the extraction of plutonium onto Bio-Rad AG 1-X8 anion exchange resin with the extraction of americium using the TRU Resin. This method was tested on three triplicate sets of QAP air filters and two triplicate sets of QAP water samples. The recoveries ranged from 70 to 90 percent, and the results were identical to those obtained by the existing methods. The time required to perform the analysis for americium was shortened from 5 weeks to 1 week. 


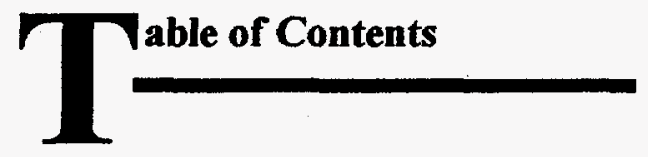

Pages

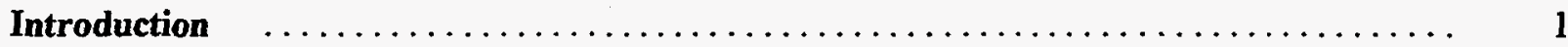

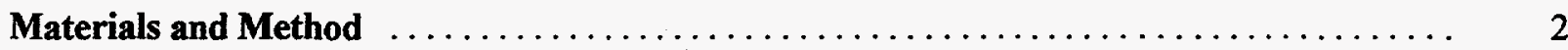

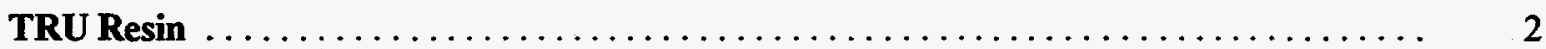

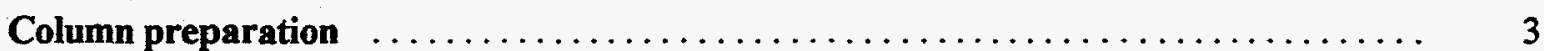

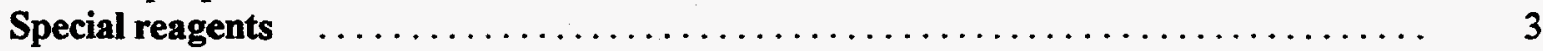

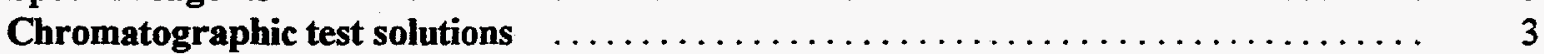

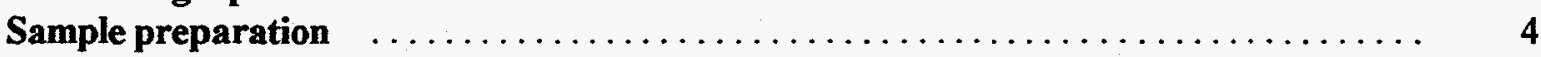

Separation scheme $\ldots \ldots \ldots \ldots \ldots \ldots \ldots \ldots \ldots \ldots \ldots \ldots \ldots \ldots \ldots \ldots \ldots \ldots \ldots \ldots \ldots$

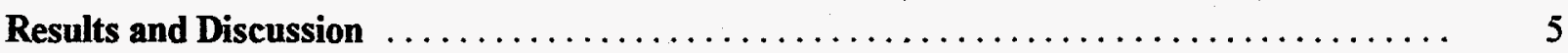

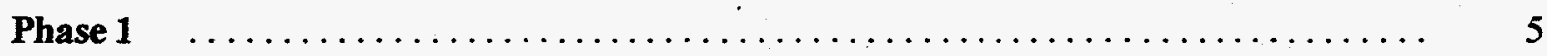

Behavior of Aqueous Solutions of Americium, Plutonium, and Uranium on the TRU Resin 6

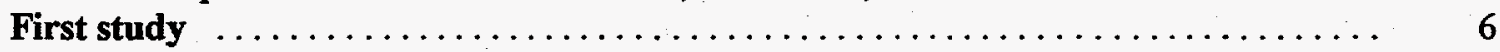

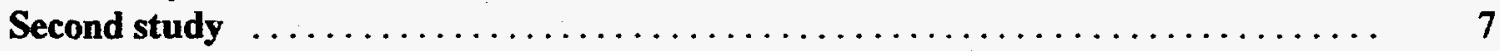

Valence Adjustment of Plutonium $\quad \ldots \ldots \ldots \ldots \ldots \ldots \ldots \ldots \ldots \ldots \ldots \ldots \ldots \ldots \ldots \ldots \ldots$

Double Treatment of the Americium Fraction $\quad \ldots \ldots \ldots \ldots \ldots \ldots \ldots \ldots \ldots \ldots$

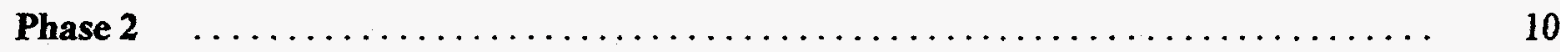

Determination of Americium in QAP-AF and QAP-Wa $\ldots \ldots \ldots \ldots \ldots \ldots \ldots \ldots \ldots$

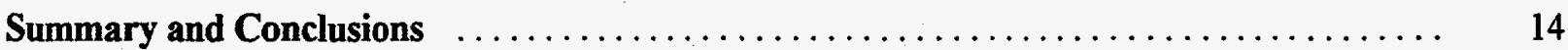

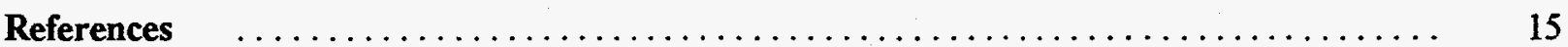

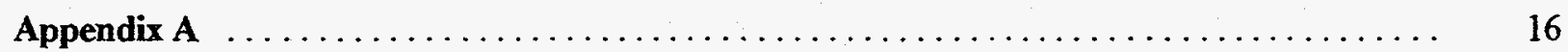

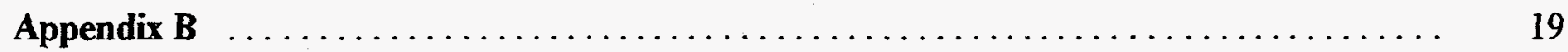




\section{NTRODUCTION}

Quantitative determination of transuranic elements in environmental matrices presents problems due partly to the nature of their nuclear emissions and partly to chemical similarities. Many isotopes of interest are $\alpha$ emitters and therefore $\alpha$ spectrometry is the most suitable method of analysis, providing both quantitative and qualitative information about the nuclides in the sample. However, a good measurement source for $\alpha$ spectrometry has to satisfy certain specific requirements. First, the $\alpha$ emitter has to be separated from the matrix to prevent self-absorption and energy degradation of the $\alpha$ particles. Second, the $\alpha$ emitter of interest has to be isolated from any other $\alpha$ emitters with similar energy peaks that cannot be resolved by the spectrometry system. For example, the $\alpha$ particles from ${ }^{241} \mathrm{Am}$ cannot be distinguished from those released by ${ }^{238} \mathrm{Pu}$, since both have energies of approximately $5.45 \mathrm{MeV}$. Consequently, in order to remove any ambiguity in the interpretation of a spectrum of $\alpha$ energies observed for a given sample we must rely on the effectiveness of the chemical separation of the interfering nuclides from each other.

Once the sample is solubilized and equilibrated with the appropriate tracers, the nuclide of interest can be isolated from the matrix and from nuclides of other elements by a series of coprecipitations, by solvent extractions, or by the use of ion-exchange chromatography. Many schemes have been developed which combine one or more of these techniques (O'Malley, 1994). All of these methods have similar drawbacks in that they are time-consuming, the chemical recovery is never $100 \%$ (and use of tracers is therefore necessary), and, in addition, large quantities of hazardous waste are usually generated. Any new material or approach which addresses even one of these major problems is worth investigating.

Reduction in time would increase our capability for analyzing the large number of samples anticipated in restoration and waste management programs. If a method was quantitative, tracers could be eliminated, which would reduce costs and remove sources of uncertainties associated with the calibration and the aliquoting of the tracer solutions. Any significant reduction in the waste stream produced is in compliance with the DOE waste minimization and pollution prevention policy and would be achieved by the most desirable option, namely source reduction.

EIChroM Industries has introduced a number of extraction chromatographic materials which demonstrate quantitative recovery, analysis time reduction and minimization of hazardous waste (Horwitz et al., 1990). It was the objective of this project to evaluate the performance of one such material, TRU Resin, for the determination of americium, plutonium and uranium in air filter and water samples. According to Horwitz et al. (1990) the organophosphorus extractant present in TRU Resin is $100 \%$ effective as an adsorber for all actinides present in acidic aqueous solutions. The extraction of all actinides in one step would represent a significant reduction in the time required for analysis. Once the actinides are removed from the sample matrix, they could be selectively desorbed by eluting with appropriate solutions and then prepared for $\alpha$ spectrometry. The stated $100 \%$ efficiency of the adsorption and the desorption steps would eliminate the need for tracers. The eluting solutions are in general very dilute and the volumes are much lower then those used in the conventional ion-exchange methods, and, therefore, we should observe a very significant reduction in the waste stream.

In the Phase 1 of this study test solutions containing tracers only and EML Quality Assurance Program (QAP) water samples of known composition (with and without tracers added) were used to evaluate and validate the claims made by EIChroM. Our attention was focused on two factors. The first was the effectiveness of the adsorption and the desorption steps in terms of the chemical recovery. The second factor dealt with the effectiveness of the chemical separation of one actinide from another, which 
is necessary for a nonambiguous interpretation of the $\alpha$ spectrogram obtained for each eluate.

The QAP water samples (QAP-Wa) were prepared at EML by adding known quantities of calibrated solutions of the nuclides of interest to a known volume of $1 \mathrm{M} \mathrm{HCl}$ and mixing them thoroughly. The activities of the nuclides were calculated using appropriate dilution factors. Initial sample homogeneity was tested using gamma-ray spectroscopy. The activities were also confirmed by radiochemical analysis of $\alpha$ and B emitters using methods found in the EML Procedures Manual (Chieco et al., 1992). The glass fiber air filters (QAP-AF) were prepared by placing $1210-\mu \mathrm{L}$ aliquots of a calibrated stock solution on each filter and drying them. The aliquots were dispensed using an automated system to assure quantitative and geometric uniformity. Each filter was counted on a gamma-ray spectrometer and utilized for program needs if the results were within specified acceptance criteria. Several randomly chosen filters were analyzed radiochemically.

As a result of the observations made during Phase 1, a second phase of this study was initiated, consisting of developing and validating a method for the determination of americium in QAP water and air filter samples. This method would be included in a revised edition of the EML Procedures Manual and thus be available to general public. The Phase 1 and 2 results are included in this report.

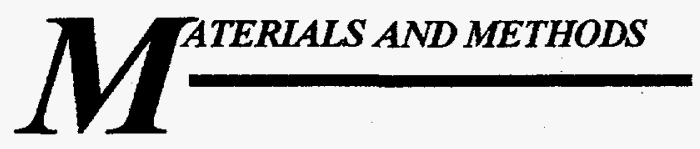

\section{TRU Resin}

The extractant in the TRU Resin chromatographic material is octyl (phenyl)-NAN-diisobutylcarbamoylmethylphosphene oxide (CMPO), which is dissolved in tributyl phosphate (TBP) to make a $0.75 \mathrm{M}$ solution and then is placed and supported on an inert substrate (Amberlite XAD-7). Combining CMPO with TBP creates a new mixed solvent system with following properties:

1. enhanced distribution ratios of $\mathrm{Am}^{+3}\left(\mathrm{D}_{\mathrm{Am}}\right)$ in the range of 0.5 to $6 \mathrm{M} \mathrm{HNO}_{3}$,

2. suppressed $D_{\text {Am }}$ at low acidity, and

3. maximum $\mathrm{D}_{\mathrm{Am}}$ at $2 \underline{\mathrm{M}} \mathrm{HNO}_{3}$.

All actinides are extracted from the loading solution, which is usually $2 \mathrm{M} \mathrm{HNO} \mathrm{HN}_{3}$ and $0.5 \mathrm{M} \mathrm{Al}\left(\mathrm{NO}_{3}\right)_{3}$. $\mathrm{Al}\left(\mathrm{NO}_{3}\right)_{3}$ is added to enhance americium sorption. Separation of the actinides is achieved by choosing an appropriate eluting solution.

The resin used for this study has a particle size ranging from 125 to $150 \mu \mathrm{m}$. Currently, the manufacturer offers TRU Resin in two particle size ranges, $100-150 \mu \mathrm{m}$ and 50-100 $\mu \mathrm{m}$. The smaller average diameter of the particles causes a decrease in the rate of elution and an increase in the breakthrough volume, from 50 free column volumes (FVC) for the medium particles to $65 \mathrm{FVC}$ for the smaller particles. In addition, the elution band width for americium decreases somewhat with the smaller diameter particles which results in a reduction of the total volume needed to strip americium from the column. It is our recommendation that for routine analysis of water and air filters the particle size chosen is as close as possible to the one used in this study, which would mean the $100-150 \mu \mathrm{m}$ range. 


\section{COLUMN PREPARATION}

An 8-mL polyethylene disposable transfer pipette with a fine tip was used to contain the resin. The top of the bulb was removed to create a funnel. A small glass wool plug was inserted through the top all the way to the base of the pipette to support the resin. The barrel dimensions $(\sim 6.5 \times 100 \mathrm{~mm})$ were such that $\sim 0.5 \mathrm{~g}$ of dry resin was required to fill it almost to the top. The resin was first placed in a small beaker, covered with deionized water and allowed to equilibrate at least overnight. On the day of the analysis the polyethylene pipette was placed in a holder and filled with the presoaked resin. The column had to be used immediately after assembling since there was no stop cock that could be turned to prevent the solution from running out in case of interruption. If a column was allowed to dry out, it would have to be discarded due to the problems associated with trying to re-wet the resin inside the column.

However, with care this problem was easily avoided since the whole procedure of assembling the column, washing the resin, loading the sample and stripping the individual fractions never took more than 2-3 hours.

\section{SPECIAL REAGENTS}

1. Column-feed solution, $0.5 \mathrm{M} \mathrm{Al}\left(\mathrm{NO}_{3}\right)_{3}$ in $2 \mathrm{M} \mathrm{HNO}$ - place $18.76 \mathrm{~g}$ of $\mathrm{Al}\left(\mathrm{NO}_{3}\right)_{3} \cdot 9 \mathrm{H}_{2} \mathrm{O}$ (certified $\mathrm{ACS}$ ) in a $100-\mathrm{mL}$ volumetric flask and add $2 \mathrm{M} \mathrm{HNO}_{3}$ to the mark. Shake to mix thoroughly.

2. Bioxalate strip solution, $0.1 \mathrm{M} \mathrm{NH}_{4} \mathrm{HC}_{2} \mathrm{O}_{4}$ - combine $50 \mathrm{~mL}$ of aqueous solution containing $0.71 \mathrm{~g}$ of $\left(\mathrm{NH}_{4}\right)_{2} \mathrm{C}_{2} \mathrm{O}_{4} \cdot \mathrm{H}_{2} \mathrm{O}$ with $50 \mathrm{~mL}$ of aqueous solution containing $0.63 \mathrm{~g}$ of $\mathrm{H}_{2} \mathrm{C}_{2} \mathrm{O}_{4} \cdot 2 \mathrm{H}_{2} \mathrm{O}$ (both certified ACS).

3. $2 \mathrm{M} \mathrm{HNO}_{3}-125 \mathrm{~mL} \mathrm{HNO}_{3}$ diluted to $1 \mathrm{~L}$ with $\mathrm{H}_{2} \mathrm{O}$.

4. $1 \mathrm{M} \mathrm{HNO}_{3}-62.5 \mathrm{~mL} \mathrm{HNO}_{3}$ diluted to $1 \mathrm{~L}$ with $\mathrm{H}_{2} \mathrm{O}$.

5. $0.025 \mathrm{M} \mathrm{HNO}_{3}-25 \mathrm{~mL} 1 \mathrm{M} \mathrm{HNO}_{3}$ diluted to $1 \mathrm{~L}$ with $\mathrm{H}_{2} \mathrm{O}$.

6. ${ }^{243} \mathrm{Am}$ tracer solution, about $0.2 \mathrm{~Bq} \mathrm{~g}^{-1}$ in a dispensing bottle.

7. ${ }^{242} \mathrm{Pu}$ tracer solution, about $1 \mathrm{~Bq} \mathrm{~g}^{-1}$ in a dispensing bottle.

8. ${ }^{232} \mathrm{U}$ tracer solution, about $0.2 \mathrm{~Bq} \mathrm{~g}^{-1}$ in a dispensing bottle.

\section{CHROMATOGRAPHIC TEST SOLUTIONS}

Several times, one or two nuclides were loaded onto the column and eluted with appropriate strip solutions. The objective was to observe the interaction of the nuclide (or nuclides) of interest with the resin without any interference from a sample matrix. Calibrated solutions of plutonium and americium isotopes were introduced onto the column, the eluted fractions were analyzed and the chemical recovery was determined. In an effort to simulate real-life conditions, the very small amount of the calibrated solution was first treated with $\mathrm{HNO}_{3}$, evaporated to dryness and the residue was redissolved in $3 \mathrm{~mL}$ of the column-feed solution. 


\section{SAMPLE PREPARATION}

QAP-Water - 100 to $500 \mathrm{~mL}$ aliquots of QAP-Wa were transferred to beakers of appropriate sizes. Tracers (known quantities of isotopes of ${ }^{242} \mathrm{Pu}$ or ${ }^{236} \mathrm{Pu},{ }^{243} \mathrm{Am}$, and ${ }^{232} \mathrm{U}$ ) could be added here at this time. The samples were first slowly reduced in volume and transferred to $50-\mathrm{mL}$ beakers, then evaporated to dryness and wet-ashed with several additions of $\mathrm{HNO}_{3}$. Finally, the dry residue was redissolved in $3 \mathrm{~mL}$ of the column-feed solution.

QAP-Air Filter - The glass fiber air filters were used in Phase 2 only. They were treated according to the procedure Plutonium-01 (Chieco et al., 1992), which was modified in two ways. First, ${ }^{243}$ Am tracer was added in addition to the plutonium tracer to allow for eventual determination of ${ }^{241} \mathrm{Am}$ in the sample. Second, steps involving the use of HF were omitted. Once the solution containing the ions leached from the air filter was adjusted to $7.5 \mathrm{M} \mathrm{HNO}_{3}$, it was then processed according to the EML procedure Pu- 11 , in which a Bio-Rad AG 1-X8 anion-exchange resin is used to separate plutonium from all other ions. As the sample solution passes through the column, plutonium is adsorbed on the resin. The eluate, which contains all other ions, including americium, is combined with the $120 \mathrm{~mL}$ of $7.5 \mathrm{M} \mathrm{HNO}$ rinse. That solution was evaporated and redissolved in $3 \mathrm{~mL}$ of the column-feed solution.

\section{SEPARATION SCHEME}

The following separation scheme was used in Phase 1 of this study. This scheme was evaluated using both the chromatographic test solutions of single nuclides as well as radiochemically characterized QAP water samples.

Step 1: Assemble the adsorption column, as described in Column Preparation.

Step 2: Prepare the column by washing with $9 \mathrm{~mL}$ of $0.1 \mathrm{M} \mathrm{NH}_{4} \mathrm{HC}_{2} \mathrm{O}_{4}$ (fraction 1), followed by $15 \mathrm{~mL}$ of $2 \mathrm{M} \mathrm{HNO}_{3}$ (fraction 2). Let each fraction reach the top of the resin bed before adding the next one. Discard both effluents.

Step 3: Load the column with the sample dissolved in the $3 \mathrm{~mL}$ of the column-feed solution, as described in sample preparation. Wash the beaker with $3 \mathrm{~mL}$ of the column-feed solution and add to the column. Collect the effluent as fraction 3.

Step 4: Rinse the column with $8 \mathrm{~mL}$ of $2 \mathrm{M} \mathrm{HNO}_{3}$ and collect the effluent as fraction 4.

Step 5: Rinse the column with $8 \mathrm{~mL}$ of $1 \mathrm{M} \mathrm{HNO}_{3}$ and collect the effluent as fraction 5.

Step 6: Strip the americium with three 3-mL portions of $0.025 \mathrm{M} \mathrm{HNO}_{3}$ and collect this eluate as fraction 6.

Step 7: Strip the plutonium and uranium with $15 \mathrm{~mL}$ of $0.1 \mathrm{M} \mathrm{NH}_{4} \mathrm{HC}_{2} \mathrm{O}_{4}$ and collect this eluate as fraction 7.

Every fraction to be analyzed by $\alpha$ spectrometry was evaporated to dryness and carefully converted to $\mathrm{HCl}$. If the eluate contained oxalate ions, as would be the case with fraction 7 , that fraction was first wet-ashed with $\mathrm{HNO}_{3}$ to destroy the oxalate. Once the sample was converted to $\mathrm{HCl}$, it was evaporated 
slowly to dryness and then transferred to a plastic culture tube with $1 \mathrm{M} \mathrm{HCl}$. The G-01 procedure for microprecipitation on $\mathrm{NdF}_{3}$ (Chieco et al., 1992) was followed with subsequent analysis by $\alpha$ spectrometry. Fraction 7 containing plutonium and uranium was microprecipitated from $\mathrm{HCl}$ solution without adjusting the oxidation state of uranium. Under these conditions, uranium remains in the solution and, therefore, was expected to be found in the filtrate obtained during the microprecipitation procedure. That filtrate was collected, treated with $\mathrm{HNO}_{3}$ to remove $\mathrm{HF}$ and converted to $\mathrm{HCL}$. Uranium was then microprecipitated on $\mathrm{NdF}_{3}$ in the presence of $\mathrm{TiCl}_{3}$ and analyzed by $\alpha$ spectrometry.

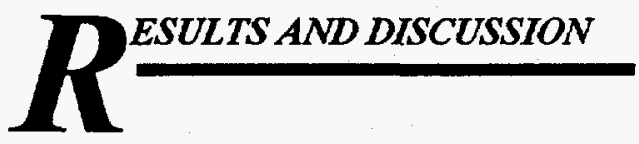

\section{PHASE 1}

The separation scheme proposed by EIChroM and utilized in this phase was expected to separate plutonium and uranium from americium. After passing the sample through the TRU Resin column the actinides would be adsorbed on the resin. Americium was expected to desorb with very dilute nitric acid (fraction 6), while plutonium and uranium would elute with the bioxalate solution (fraction 7). Both fractions would be microprecipitated as described in the separation scheme. Normally uranium is present in a +6 oxidation state, which does not form an insoluble precipitate with a fluoride ion. However, when uranium is reduced to a lower oxidation state with $\mathrm{TiCl}_{3}$, it will microprecipitate on $\mathrm{NdF}_{3}$. The separation scheme used here was to be evaluated for its ability to separate americium from the other two actinides, namely plutonium and uranium. Separation of natural uranium from plutonium was to be achieved through the microprecipitation process.

Horwitz et al. (1990) used electrodeposition to prepare the actinides for $\alpha$ spectrometry, while at EML microprecipitation with $\mathrm{NdF}_{3}$ is the method of choice. Before any conclusions could be drawn from the experimental results, it was necessary to evaluate the efficiency of the microprecipitation. Two $10.0-\mathrm{mL}$ aliquots containing $\sim 7 \mathrm{mBq}^{242} \mathrm{Pu} \mathrm{mL} \mathrm{m}^{-1}$ and $\sim 6 \mathrm{mBq}^{236} \mathrm{Pu} \mathrm{mL}^{-1}$ were placed in 50 -mL beakers, evaporated, converted to $\mathrm{HCl}$ and then microprecipitated on $\mathrm{NdF}_{3}$ according to EML procedure G-03 (Microprecipitation Source Preparation for $\alpha$ Spectrometry, Chieco et al., 1992). The results are summarized in Table 1.

\section{TABLE 1}

RECOVERIES OF ${ }^{242} \mathrm{Pu}$ AND ${ }^{236} \mathrm{Pu}$ AFTER MICROPRECIPITATION ${ }^{2}$

\begin{tabular}{lcc}
\hline & Aliquot 1 & Aliquot 2 \\
\hline$\%$ recovery of ${ }^{242} \mathrm{Pu}$ & $83.0 \pm 2.9$ & $85.2 \pm 3.0$ \\
$\%$ recovery of ${ }^{236} \mathrm{Pu}$ & $74.1 \pm 2.6$ & $82.0 \pm 2.9$ \\
\hline
\end{tabular}

${ }^{a}$ The error term includes the counting error, the detector efficiency uncertainty and the uncertainty in the activity added, all terms combined according to the accepted methods for propagation of indeterminate errors. 
The results shown here tell us that the microprecipitation step is not $100 \%$ efficient and that we can expect the sum of activities recovered from all possible fractions (the mass balance calculations) to represent as little as $75 \%$ of the activity added.

\section{BEHAVIOR OF AQUEOUS SOLUTIONS OF AMERICIUM, PLUTONIUM, AND URANIUM ON TRU RESIN}

First study - QAP-Wa solutions are prepared with acidified deionized water and standardized solutions of radioactive nuclides. Since a sufficient amount of QAP-9009-Wa was available, it represented a ready-made chromatographic test solution, which contained all the actinides of interest and required minimal sample preparation. Three aliquots $(200 \mathrm{~mL}, 300 \mathrm{~mL}$, and $500 \mathrm{~mL}$ ) of previously analyzed QAP-9009-Wa were evaporated and processed using the separation scheme described here. Initially only fractions 6 (americium) and 7 (plutonium and uranium) were microprecipitated and counted on an $\alpha$-spectrometer. No tracers were added and the recoveries were calculated from the known activities of QAP-9009-Wa. The recoveries and identities of the actinides found in fractions 6 and 7 are listed in Table 2. The final microprecipitated sources were counted for a sufficient time so that the Poisson error of a major peak was no more than $\pm 3 \%$. The smaller peaks, if present, would then have Poisson errors as much as $\pm 20 \%$.

The results showed a recovery rate of $65-80 \%$ for each of the actinides present $\left({ }^{239} \mathrm{Pu},{ }^{241} \mathrm{Am}\right.$ and natural uranium). In addition, there was a crossover between fractions, where 1 to $5 \%$ of a given nuclide was found in another fraction. In order to get a more complete picture of the mass balance, the rinse fractions and the resin were analyzed for the missing nuclides. The results are included in Table 2. No actinides were found in any of the rinse fractions. Traces of plutonium and uranium ( $1 \%$ or less) were found on the stationary phase of the resin (after dry-ashing).

TABLE 2

RECOVERIES OF ${ }^{241} \mathrm{Am},{ }^{239} \mathrm{Pu}$ AND Nat U FROM QAP-9009-Wa USING TRU RESIN

\begin{tabular}{cccc}
\hline Fraction & Aliquot 1 & Aliquot 2 & Aliquot 3 \\
$(200 \mathrm{~mL})$ & $(300 \mathrm{~mL})$ & $(500 \mathrm{~mL})$ \\
\hline & & & \\
Am fraction & $65.4 \%{ }^{241} \mathrm{Am}$ & $69.7 \%{ }^{241} \mathrm{Am}$ & $74.8 \%{ }^{241} \mathrm{Am}$ \\
(fraction 6) & $2.3 \%{ }^{239} \mathrm{Pu}$ & $3.1 \%{ }^{239} \mathrm{Pu}$ & $3.7 \%{ }^{239} \mathrm{Pu}$ \\
Pu fraction & $74.7 \%{ }^{239} \mathrm{Pu}$ & $76.6 \%{ }^{239} \mathrm{Pu}$ & $72.7 \%{ }^{239} \mathrm{Pu}$ \\
(fraction 7) & $3.6 \%{ }^{241} \mathrm{Am}$ & $1.2 \%{ }^{241} \mathrm{Am}$ & $1.4 \%{ }^{241} \mathrm{Am}$ \\
Nat U fraction & $70.7 \% \mathrm{Nat} \mathrm{U}$ & $79.7 \% \mathrm{Nat} \mathrm{U}$ & $49.5 \% \mathrm{Nat} \mathrm{U}$ \\
(fraction 7) & $3.6 \%{ }^{241} \mathrm{Am}$ & - & $0.5 \%{ }^{241} \mathrm{Am}$ \\
& $4.7 \%{ }^{239} \mathrm{Pu}$ & $1.0 \%{ }^{239} \mathrm{Pu}$ & $0.9 \%{ }^{239} \mathrm{Pu}$ \\
HNO $_{3}$ rinse & - & - & - \\
Filtrate $^{\mathrm{b}}$ & - & $4.0 \% \mathrm{Nat} \mathrm{U}$ & $28.0 \% \mathrm{Nat} \mathrm{U}$ \\
Stationary phase $^{\mathrm{c}}$ & $11 \%{ }^{239} \mathrm{Pu}$ & $1.2 \%{ }^{239} \mathrm{Pu}$ & $0.7 \%{ }^{239} \mathrm{Pu}$ \\
& & $1.0 \% \mathrm{Nat} \mathrm{U}$ & $0.8 \% \mathrm{Nat} \mathrm{U}$ \\
\hline
\end{tabular}

\footnotetext{
a From Steps 4 and 5.

${ }^{b}$ From natural uranium microprecipitation, wet-ashed and microprecipitated again in the presence of $\mathrm{TiCl}_{3}$.

${ }^{\circ}$ Resin dissolved in methanol, evaporated and dry-ashed at $700^{\circ} \mathrm{C}$.
} 
Significant amounts of natural uranium found in the filtrate could be accounted for by incomplete transfer of natural uranium from the Teflon beaker to the culture tube during the first microprecipitation step.

On a mass balance basis $\sim 20 \%$ or more of the actinides were not recovered, but that could be caused by the losses associated with the microprecipitation step.

Second study - Three aliquots $(100 \mathrm{~mL}, 200 \mathrm{~mL}$, and $300 \mathrm{~mL})$ of QAP-9103-Wa were analyzed for ${ }^{241} \mathrm{Am},{ }^{239} \mathrm{Pu}$, and Nat $\mathrm{U}$, with addition of known quantities of ${ }^{243} \mathrm{Am},{ }^{242} \mathrm{Pu}$ and ${ }^{232} \mathrm{U}$ tracers. The ${ }^{232} \mathrm{U}$ tracer also contained detectable quantities of ${ }^{228} \mathrm{Th}$. In order to eventually develop a method utilizing TRU Resin for the determination of actinides in thorium-containing samples, such as soils, it was important to find out which fraction(s) contained thorium.

\section{TABLE 3}

\section{RECOVERIES OF ${ }^{243} \mathrm{Am},{ }^{242} \mathrm{Pu}$ AND ${ }^{232} \mathrm{U}$, ADDED AS TRACERS TO QAP-9103-Wa AND EXTRACTED USING TRU RESIN}
Fraction
Aliquot 1
Aliqout 2
Aliquot 3
$(100 \mathrm{~mL})$
$(200 \mathrm{~mL})$
$(300 \mathrm{~mL})$
Blank

\begin{tabular}{ccccc}
\hline & & & \\
Am fraction & $84.7 \%{ }^{243} \mathrm{Am}$ & $81.4 \%{ }^{243} \mathrm{Am}$ & $75.0 \%{ }^{243} \mathrm{Am}$ & $79.5 \%{ }^{243} \mathrm{Am}$ \\
(fraction 6) & $3.6 \%{ }^{242} \mathrm{Pu}$ & $7.8 \%{ }^{242} \mathrm{Pu}$ & $6.4 \%{ }^{242} \mathrm{Pu}$ & $1.2 \%{ }^{242} \mathrm{Pu}$ \\
$\begin{array}{c}\text { Pu fraction } \\
\text { (fraction 7) }\end{array}$ & $64.1 \%{ }^{242} \mathrm{Pu}$ & $71.7 \%{ }^{242} \mathrm{Pu}$ & $64.3 \%{ }^{242} \mathrm{Pu}$ & $76.8 \%{ }^{242} \mathrm{Pu}$ \\
$\begin{array}{c}\text { Nat U fraction } \\
\text { (fraction 7) }\end{array}$ & $87.8 \%{ }^{232} \mathrm{U}$ & $86.4 \%{ }^{232} \mathrm{U}$ & $84.9 \%{ }^{232} \mathrm{U}$ & $83.0 \%{ }^{232} \mathrm{U}$ \\
\hline
\end{tabular}

The following are some of the comments that can be made about the data presented here:

1. The crossover between fractions persisted to the same extent as observed in the first study, and adjustments would be needed in the separation scheme in order to isolate the relevant chemical species more thoroughly and provide us with sources suitable for $\alpha$ spectrometry.

2. The presence of ${ }^{242} \mathrm{Pu}$ in the americium fraction implies the presence of ${ }^{239} \mathrm{Pu}$ as well. The reported ${ }^{243} \mathrm{Am}$ recoveries are based on the number of counts observed in the ${ }^{243} \mathrm{Am}$ region of interest, which overlaps with the ${ }^{239} \mathrm{Pu}$ region of interest and cannot be resolved by our $\alpha$ spectrometry system. Since the total activity of each plutonium isotope is known, the number of counts in the ${ }^{243} \mathrm{Am}$ region of 
interest could be decreased by the estimated contributions made by disintegrations of ${ }^{239} \mathrm{Pu}$. These corrections would represent on the average a $\sim 5 \%$ decrease in the calculated ${ }^{243} \mathrm{Am}$ recoveries.

3. Traces of ${ }^{228} \mathrm{Th}$ and its daughters, such as ${ }^{224} \mathrm{Ra},{ }^{220} \mathrm{Rn},{ }^{216} \mathrm{Po}$, were found in the plutonium fraction only of each aliquot. The existing separation scheme did not provide for the separation of thorium from plutonium, which is necessary for the nonambiguous identification of the peaks observed in the $\alpha$-spectrogram of the plutonium fraction.

\section{VALENCE ADJUSTMENT OF PLUTONIUM}

Plutonium is known to exist in several oxidation states. The most stable states are $+3,+4$ and +6 . It is a well known fact that $\mathrm{Pu}^{+4}$ disproportionates to $\mathrm{Pu}^{+3}$ and $\mathrm{Pu}^{+6}$, and that the rate of this reaction changes with the $\mathrm{pH}$ and the nature and concentration of the anions in the solution. Consequently, under certain conditions, $\mathrm{Pu}^{+3}, \mathrm{Pu}^{+4}$, and $\mathrm{Pu}^{+6}$ may coexist in comparable concentrations (Milyukova et al., 1969). The chemical behavior of the various plutonium ions may differ significantly from one ion to another. A hypothesis was formulated that this multiplicity of oxidation states was responsible for the crossover of some of the plutonium into the americium fraction. To test this hypothesis, an attempt was made to determine whether a valence adjustment could eliminate this crossover. An assumption was made that $\mathrm{Pu}^{+3}$ followed $\mathrm{Am}^{+3}$ because of their identical charges and therefore an oxidizing environment was needed to bring as many plutonium ions to +4 oxidation state as possible.

Three 200-mL aliquots of QAP-9103-Wa were taken to dryness and redissolved in $10 \mathrm{~mL}$ deionized (DI) $\mathrm{H}_{2} \mathrm{O}$, followed by addition the of $\sim 0.5 \mathrm{~g}$ of $\mathrm{NaNO}_{2}$. After adding $5-10 \mathrm{~mL}$ of $7.5 \mathrm{M} \mathrm{HNO}$ the aliquots were taken to dryness, redissolved in $3 \mathrm{~mL}$ of the column-feed solution and loaded onto the prepared column. A standard elution procedure was followed. Each fraction was microprecipitated and counted using $\alpha$ spectrometry. In addition, the resin from each column was placed in a platinum crucible and dry-ashed at $600^{\circ} \mathrm{C}$. The residue was redissolved in $7.5 \mathrm{M} \mathrm{HNO}_{3}$, converted to $\mathrm{HCl}$, and microprecipitated on $\mathrm{NdF}_{3}$ in the presence of $\mathrm{TiCl}_{3}$. The minimal activity (less than $1 \%$ of the total) found on each resin aliquot demonstrated that the elution procedure was essentially $100 \%$ effective. The results are shown in Table 4. The data in Table 4 (see page 9) shows that the valence adjustment did not eliminate the plutonium crossover into the americium fraction.

\section{DOUBLE TREATMENT OF THE AMERICIUM FRACTION}

The fraction of plutonium found in the americium eluate was fairly constant over the range of the activities of plutonium in the samples $(0.1 \mathrm{~Bq}$ to $0.5 \mathrm{~Bq}$ per aliquot). This data indicates that perhaps the partition constant for plutonium between the resin and the $0.025 \mathrm{M} \mathrm{HNO}_{3}$ is not large enough to achieve good separation of plutonium and americium. However, an additional treatment of the americium fraction on a fresh column might remove the remaining plutonium and render the sample pure enough for $\alpha$ spectrometry. To determine whether this was true, the following steps were taken. Four samples were prepared containing increasing amounts of ${ }^{242} \mathrm{Pu}(0.07-0.25 \mathrm{~Bq})$ and $\sim 0.07 \mathrm{~Bq}{ }^{243} \mathrm{Am}$. Each sample was treated with $\mathrm{HNO}_{3}$ several times, evaporated to dryness and redissolved in $3 \mathrm{~mL}$ of the column-feed solution. Each load solution was placed onto a TRU Resin column and a standard procedure for washing and elution of plutonium and americium fractions was followed. The four plutonium fractions (one from each column) were prepared for $\alpha$ spectrometry. The americium fractions were evaporated, redissolved in $3 \mathrm{~mL}$ of the column-feed solution and loaded onto fresh TRU Resin columns. The plutonium and americium fractions were eluted according to the same scheme and prepared for $\alpha$ spectrometry. The results are summarized in Table 5. 
TABLE 4

RECOVERIES OF ${ }^{241}$ AMERICIUM, ${ }^{239} \mathrm{Pu}$ AND Nat U FROM QAP-9103-Wa
WITH NaNO ${ }_{2}$ PRETREATMENT

\begin{tabular}{|c|c|c|c|}
\hline Fraction & $\begin{array}{l}\text { Aliquot } 1 \\
(200 \mathrm{~mL})\end{array}$ & $\begin{array}{l}\text { Aliquot } 2 \\
(200 \mathrm{~mL})\end{array}$ & $\begin{array}{l}\text { Aliquot } 3 \\
(200 \mathrm{~mL})\end{array}$ \\
\hline $\begin{array}{l}\text { Am fraction } \\
\text { (fraction 6) }\end{array}$ & $\begin{array}{c}83.8 \%{ }^{241} \mathrm{Am} \\
2.4 \%{ }^{239} \mathrm{Pu}\end{array}$ & $\begin{array}{c}82.2 \%{ }^{241} \mathrm{Am} \\
3.6 \%{ }^{239} \mathrm{Pu}\end{array}$ & $\begin{array}{c}80.0 \%{ }^{241} \mathrm{Am} \\
5.8 \%{ }^{239} \mathrm{Pu}\end{array}$ \\
\hline $\begin{array}{c}\text { Pu fraction } \\
\text { (fraction 7) }\end{array}$ & $\begin{array}{l}74.7 \%{ }^{239} \mathrm{Pu} \\
2.3 \%{ }^{241} \mathrm{Am}\end{array}$ & $\begin{array}{c}54.9 \%{ }^{239} \mathrm{Pu} \\
1.2 \%{ }^{241} \mathrm{Am}\end{array}$ & $\begin{array}{c}65.9 \%{ }^{239} \mathrm{Pu} \\
1.9 \%{ }^{241} \mathrm{Am}\end{array}$ \\
\hline $\begin{array}{l}\text { Nat } U \text { fraction } \\
\text { (fraction } 7 \text { ) }\end{array}$ & $\begin{array}{c}76.4 \% \text { Nat U } \\
0.5 \%{ }^{239} \mathrm{Pu}\end{array}$ & $\begin{array}{c}65.5 \% \text { Nat U } \\
0.1 \%{ }^{239} \mathrm{Pu}\end{array}$ & $\begin{array}{c}80.4 \% \text { Nat U } \\
0.6 \%{ }^{239} \mathrm{Pu}\end{array}$ \\
\hline sin ashed at $-600^{\circ} \mathrm{C}$ & $\begin{array}{l}0.60 \% \text { of total } \\
\text { activity* }\end{array}$ & $\begin{array}{l}0.58 \% \text { of total } \\
\text { activity* }\end{array}$ & $\begin{array}{c}0.69 \% \text { of tota } \\
\text { activity }\end{array}$ \\
\hline
\end{tabular}

${ }^{*}$ Total activity is equal to the sum of activities of ${ }^{241} \mathrm{Am},{ }^{239} \mathrm{Pu}$, and $\mathrm{Nat} U$ expected to be present in $200 \mathrm{~mL}$ of QAP-9103-Wa.

It can be seen that the americium fraction contains much less plutonium (anywhere from $0.04 \%$ to $0.16 \%$ of the added amount) than when a single column separation was used. However, the double treatment of the americium fraction is not $100 \%$ effective in removing plutonium. If a sample's plutonium activity is significantly greater than that due to the presence of americium, as is often the case, even a very small fraction of plutonium activity would interfere with the energy spectrum of the americium isotopes.

It is important to note that while the amount of plutonium in the americium fraction has been decreased, the recovery of americium does not seem to be diminished by this double treatment and still ranges from 70 to $80 \%$. Consequently, the double treatment of the americium fraction has some merit, but more work needs to be done on the limitations and the applicability of this approach to the various types of samples encountered at EML.

In conclusion, the sequential determination of plutonium (with natural uranium) and americium using TRU Resin cannot be accomplished with the separation scheme proposed in this study. The main problem is the persistent appearance of traces of plutonium in the americium fraction and vice versa. 
TABLE 5

RECOVERIES OF ${ }^{242} \mathrm{Pu}$ AND ${ }^{243}$ Am AFTER DOUBLE TREATMENT

OF THE AMERICIUM FRACTION

\begin{tabular}{|c|c|c|c|c|}
\hline Aliquot No. & Tracer added & First $\mathrm{Pu}$ fraction & $\begin{array}{l}\text { Second } \mathrm{Pu} \\
\text { fraction }\end{array}$ & Am fraction \\
\hline 1 & $\begin{array}{l}0.0675 \mathrm{~Bq}^{242} \mathrm{Pu} \\
0.0649 \mathrm{~Bq}^{243} \mathrm{Am}\end{array}$ & $\begin{array}{c}\text { not } \\
\text { available }\end{array}$ & $\begin{array}{l}0.36 \%{ }^{242} \mathrm{Pu} \\
0.96 \%{ }^{243} \mathrm{Am}\end{array}$ & $\begin{array}{r}0.16 \%{ }^{242} \mathrm{Pu} \\
83.75 \%{ }^{243} \mathrm{Am}\end{array}$ \\
\hline 2 & $\begin{array}{l}0.131 \mathrm{~Bq}^{242} \mathrm{Pu} \\
0.0747 \mathrm{~Bq}^{243} \mathrm{Am}\end{array}$ & $\begin{array}{l}75.37 \%{ }^{242} \mathrm{Pu} \\
11.59 \%{ }^{243} \mathrm{Am}\end{array}$ & $\begin{array}{l}\text { none detected } \\
1.52 \%{ }^{243} \mathrm{Am}\end{array}$ & $\begin{array}{r}0.03 \%{ }^{242} \mathrm{Pu} \\
68.64 \%{ }^{243} \mathrm{Am}\end{array}$ \\
\hline 3 & $\begin{array}{l}0.216 \mathrm{~Bq}^{242} \mathrm{Pu} \\
0.0637 \mathrm{~Bq}^{243} \mathrm{Am}\end{array}$ & $\begin{array}{c}62.04 \%{ }^{242} \mathrm{Pu} \\
0.45 \%{ }^{243} \mathrm{Am}\end{array}$ & $\begin{array}{l}0.54 \%{ }^{242} \mathrm{Pu} \\
1.37 \%{ }^{243} \mathrm{Am}\end{array}$ & $\begin{array}{r}0.12 \%{ }^{242} \mathrm{Pu} \\
74.06 \%{ }^{243} \mathrm{Am}\end{array}$ \\
\hline 4 & $\begin{array}{l}0.255 \mathrm{~Bq}^{242} \mathrm{Pu} \\
0.0779 \mathrm{~Bq}^{243} \mathrm{Am}\end{array}$ & $\begin{array}{c}79.37 \%{ }^{242} \mathrm{Pu} \\
1.91 \%{ }^{243} \mathrm{Am}\end{array}$ & $\begin{array}{l}0.56 \%{ }^{242} \mathrm{Pu} \\
0.38 \%{ }^{243} \mathrm{Am}\end{array}$ & $\begin{array}{r}\mathbf{0 . 0 4 \%} \%{ }^{242} \mathrm{Pu} \\
75.95 \%{ }^{243} \mathrm{Am}\end{array}$ \\
\hline
\end{tabular}

\section{PHASE 2}

Determination of Americium in QAP-AF and QAP-Wa - In this Laboratory, the separation and isolation scheme for plutonium is relatively simple and short compared to the scheme for americium. Therefore, a procedure is proposed for plutonium/americium determination which would simplify and shorten the existing method and that can be applied to both water and air filters. For each matrix, the existing plutonium procedure, such as Pu-01 for air filters and $\mathrm{Pu}-10$ for water (Chieco et al., 1992), each combined with Pu-11 (ion-exchange purification) would be followed. The eluate from the ion-exchange column containing americium and all other ions except plutonium is then processed for loading onto a TRU Resin extraction column. The details of the procedure can be found in Appendix A.

The first test of this procedure was conducted using QAP-9303R-AF air filters. Three filters and a blank were analyzed for plutonium using the standard procedure ( $\mathrm{Pu}-01$ combined with $\mathrm{Pu}-11$ ) and the americium determination was accomplished using the TRU Resin. At the same time, three additional air filters were analyzed using the accepted sequential plutonium/americium method, where the eluate from the ion-exchange purification column (method $\mathrm{Pu}-11$ ) containing americium was processed for americium using an adaptation of method Am-01 (Chieco et al.,1992). The details of that adaptation can be found in Appendix B. The results of the ${ }^{241}$ Am determination using both methods are summarized in Table 6 . Recoveries of known quantities of ${ }^{243} \mathrm{Am}$ tracers added to each sample and each blank are listed as well. The error term for each calculated activity includes the Poisson error for the ${ }^{243} \mathrm{Am}$ tracer and for the ${ }^{241} \mathrm{Am}$ analyte. Other sources of uncertainties, such as that of the detector efficiency and another one of the activity of the tracer, are much smaller and therefore insignificant in comparison with the counting errors. 
TABLE 6

COMPARISON OF ${ }^{241}$ Am DETERMINATION IN QAP-9303R-AF USING STANDARD EML METHOD AND THE TRU RESIN METHOD

\begin{tabular}{lcc}
\hline \multicolumn{1}{c}{ Sample No. } & $\begin{array}{c}\text { Activity } \\
(\mathrm{Bq})\end{array}$ & $\begin{array}{c}\% \text { recovery } \\
\text { of }{ }^{243} \text { Am tracer }\end{array}$ \\
\hline EMLmethod & & \\
QAP-9303R-AF-BLK-1 & $0.0002 \pm 0.0025$ & $68.6 \pm 4.0$ \\
QAP-9303R-AF-51 & $0.0434 \pm 0.0025$ & $71.3 \pm 4.1$ \\
QAP-9303R-AF-141 & $0.0394 \pm 0.0024$ & $73.5 \pm 4.5$ \\
QAP-9303R-AF-191 & $0.0434 \pm 0.0025$ & $70.7 \pm 4.1$ \\
TRUResin method & & \\
\hline QAP-9303R-AF-BLK-2 & $0.0002 \pm 0.0001$ & $80.0 \pm 3.2$ \\
QAP-9303R-AF-81 & $0.0395 \pm 0.0021$ & $86.7 \pm 3.5$ \\
QAP-9303R-AF-101 & $0.0399 \pm 0.0021$ & $83.5 \pm 3.3$ \\
QAP-9303R-AF-161 & $0.0425 \pm 0.0022$ & $79.6 \pm 3.2$ \\
\hline
\end{tabular}

The average value of ${ }^{241} \mathrm{Am}$ activity per filter using the standard method was $0.0421 \pm 0.023 \mathrm{~Bq}^{241} \mathrm{Am}$, while the modified procedure resulted in the average value equal to $0.0406 \pm 0.0016 \mathrm{~Bq}^{241} \mathrm{Am}$ per filter. These two values differ from each other by $3.6 \%$, which is within $1 \sigma$ of either result.

The second test of this procedure was conducted using QAP-9309-AF and QAP-9309-Wa samples. The overall sequence of steps was slightly altered in order to save time without compromising the integrity of the test. Only three air filters and only three aliquots of QAP-Wa $(150 \mathrm{~mL}, 100 \mathrm{~mL}$, and $200 \mathrm{~mL}$ ) were analyzed for plutonium. Each eluate from the ion-exchange column was brought to $\sim 100 \mathrm{~mL}$ and placed in a preweighed flask with a ground-glass stopper. About half of each solution was transferred to another flask and the first flask was weighed again. Aliquot A was then analyzed for americium using the standard method, and aliquot $B$ was analyzed for americium using the TRU Resin. The results obtained from $\alpha$ spectrometry had only to be multiplied by an appropriate gravimetric factor to give results in terms of activity per filter or per $1 \mathrm{~L}$ of water. The individual results of the americium determination using both methods are presented in Table 7 for air filters and Table 8 for water.

The lowest recovery of the added tracer for the standard method approached $70 \%$, while for the TRU Resin method it never went below $80 \%$.

In the third test of this procedure, samples of QAP-8305-AF and QAP-9303-Wa were analyzed and compared with the results available from previous determinations. Both sets of results are included in Table 9. The results for QAP-9303-Wa using the Am-01 procedure were obtained by two analysts. The overall agreement between the two methods is excellent. 
In the next stage of the validation process, other analysts in the laboratory were asked to use the new procedure and their results were compared with the standard method results. Two water samples (QAP9409 and QAP-9503) and one set of air filter samples (QAP-9409) were analyzed. These results are also included in Table 9. The reported result with its associated standard deviation is the average of triplicate analysis. As was the case with a single analyst performing both sets of determinations (see QAP-9303R-AF, QAP-9309-AF and QAP-9309-Wa), no significant bias was observed.

This procedure represents tremendous savings in time and in the type and volume of the generated waste. While the existing americium procedure can take several weeks (minimum of 15 working days), the use of TRU Resin shortens this time to no more than 5 working days. The generated waste per column is limited to $23 \mathrm{~mL}$ of the $1 \mathrm{M} \mathrm{HNO}_{3}$ and $8 \mathrm{~mL}$ of the $2 \mathrm{M} \mathrm{HNO}$ solutions used to rinse the TRU Resin.

It is important to note that this procedure cannot be used on matrices with lanthanides present. The lanthanides will follow americium (and curium, which typically stays with americium) all the way through the microprecipitation and will seriously affect the resolution of the $\alpha$ spectrograph.

\section{TABLE 7}

COMPARISON OF ${ }^{241}$ Am DETERMINATION IN QAP-9309-AF USING STANDARD EML METHOD AND THE TRU RESIN METHOD

\begin{tabular}{lcc}
\hline \multicolumn{1}{c}{ Sample No. } & $\begin{array}{c}\text { Activity } \\
(\mathrm{Bq})\end{array}$ & $\begin{array}{c}\text { \% recovery } \\
\text { of }{ }^{243} \text { Am tracer }\end{array}$ \\
\hline EML method - Aliquots & & \\
Q93-AF-BLK & $0.0001 \pm 0.0002$ & $30.2 \pm 4.7$ \\
Q93-AF-062 & $0.0726 \pm 0.0041$ & $83.2 \pm 4.7$ \\
Q93-AF-063 & $0.0618 \pm 0.0036$ & $91.2 \pm 5.3$ \\
Q93-AF-064 & $0.0722 \pm 0.0042$ & $80.2 \pm 4.7$ \\
TRU-Resin method-B & & \\
\hline Q93-AF-062 & & $82.5 \pm 3.0$ \\
Q93-AF-063 & $0.064 \pm 0.003$ & $86.0 \pm 2.8$ \\
Q93-AF-064 & $0.068 \pm 0.004$ & $81.6 \pm 2.4$ \\
\hline
\end{tabular}


TABLE 8

COMPARISON OF ${ }^{241}$ Am DETERMINATION IN QAP-9309-Wa USING STANDARD EML METHOD AND THE TRU RESIN METHOD

\begin{tabular}{ccc}
\hline Sample No. & $\begin{array}{c}\text { Activity } \\
\left(\mathrm{Bq} \mathrm{L}^{-1}\right)\end{array}$ & $\begin{array}{c}\text { \% recovery } \\
\text { of }{ }^{243} \text { Am tracer }\end{array}$ \\
\hline EML method - aliquot A & & \\
Q93-Wa-BLK & & \\
Q93-Wa-043 & $0.0003 \pm 0.0002$ & $72.2 \pm 1.5$ \\
Q93-Wa-044 & $1.44 \pm 0.04$ & $86.3 \pm 1.7$ \\
Q93-Wa-045 & $1.20 \pm 0.06$ & $81.1 \pm 2.1$ \\
TRUResinmethod-aliquot B & $1.33 \pm 0.04$ & $74.1 \pm 1.4$ \\
Q93-Wa-BLK & & \\
Q93-Wa-043 & & $81.6 \pm 2.0$ \\
Q93-Wa-044 & $0.0002 \pm 0.0002$ & $94.4 \pm 1.7$ \\
Q93-Wa-045 & $1.43 \pm 0.04$ & $89.2 \pm 2.3$ \\
\hline
\end{tabular}

TABLE 9

COMPARISON OF THE RESULTS OF ${ }^{241}$ Am DETERMINATION IN WATER AND AIR FILTERS USING TWO METHODS

\begin{tabular}{cccc}
\hline $\begin{array}{c}\text { Sample } \\
\text { description }\end{array}$ & $\begin{array}{c}\text { Am-01 } \\
\text { procedure } \\
\text { (modified) }\end{array}$ & $\begin{array}{c}\text { TRU Resin } \\
\text { procedure }\end{array}$ & EML value \\
\hline Air filter (mBq filter $\left.{ }^{-1}\right)$ & & & \\
\hline 8305 & & & \\
$9303 \mathrm{R}$ & $130.0 \pm 8.00$ & $137.4 \pm 1.4$ & $130.0 \pm 8.0$ \\
9309 & $42.1 \pm 2.3$ & $40.6 \pm 1.6$ & $41.4 \pm 2.0$ \\
9409 & $65.4 \pm 6.0$ & $66.3 \pm 2.1$ & $65.4 \pm 6.0$ \\
Water (BqL-1) & $209.0 \pm 6.00$ & $214.0 \pm 0.9$ & $212.0 \pm 9.0$ \\
9303 & & & \\
9309 & & & $0.460 \pm 0.10$ \\
9409 & $0.460 \pm 0.100$ & $0.501 \pm 0.015$ & $1.390 \pm 0.06$ \\
9503 & $1.388 \pm 0.057$ & $1.383 \pm 0.050$ & $1.010 \pm 0.06$ \\
\hline
\end{tabular}

${ }^{\mathrm{a}}$ Sanderson et al., (1995) 


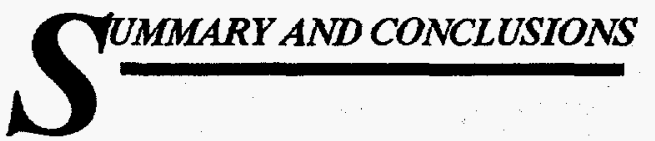

When CMPO was first introduced (Horwitz et al., 1990) as an extraction material specific for actinides, its use was limited to gross determinations of all actinides present in a sample. Because the recoveries were believed to be consistently above $90 \%$, no tracers were needed and the actinides could be eluted from the extraction column and electroplated in preparation for gross $\alpha$ counting or $\alpha$ spectrometry. Since the whole process, when applied to urine samples, could be easily completed in 3 days, this method was offered as a reliable and inexpensive way of monitoring workers for exposure to actinide elements (Nelson and Fairman, 1990). EIChroM Industries further developed this approach further and introduced a commercially available extraction chromatographic material with CMPO as the active component. This material, called TRU Resin, was expected to have two characteristics that could be of importance to EML. First, the overall efficiency of extraction of actinides from the sample, followed by desorption and electroplating in order to prepare the sample for $\alpha$ spectrometry, should be very close to $100 \%$ so that tracers would not have to be used. Second, different eluting solutions could be used to selectively strip the column of the actinides present and thus achieve their separation from each other with the use of a single column. An extraction and separation scheme for determination of plutonium, americium, and natural uranium in QAP-Wa was proposed, which would allow us to test the validity of both of these claims.

The first study was directed at determining conditions under which fractions eluted from the column would be chemically pure, that is, with a single actinide element present in a given fraction. The crossover of plutonium into the americium fraction was persistent and none of the steps tried were sufficiently successful. Adjustment of the plutonium oxidation state was tried on the assumption that the oxidation state of plutonium was affecting the extent of the crossover. Horwitz et al., (1990) made a single attempt to eliminate the crossover of plutonium into the americium fraction and did not succeed. We conclude that the crossover is primarily a function of something other than the oxidation state of plutonium. A different separation scheme could be tried, but that is beyond the scope of this study. One approach was tested, that took advantage of the fairly constant fraction of plutonium appearing in the americium fraction. This so called "double treatment" of the americium fraction resulted in a definite reduction of the extent of the crossover (from $\sim 5 \%$ to less than $0.2 \%$ ), but this approach is of limited use and its scope would have to be investigated further.

The new procedure for determination of americium in QAP-Wa and QAP-AF, which combined removal (and possible determination) of plutonium using an anion-exchange column with the use of TRU resin for extraction and isolation of americium has been shown to be very promising. Once all the techniques necessary were mastered and optimized, the recoveries for americium were always greater than $80 \%$ (Tables 6,7 , and 8 ). If this method were to be used for screening purposes only, addition of a tracer could be eliminated. However, when the acceptable error of the determination is less than $5 \%$, a tracer has to be introduced in order to correct for chemical losses. The accuracy of the new method is within $1 \sigma$ of the results obtained by the routine method used at EML (see Table 9).

This procedure allows for sequential determination of very low levels of plutonium and americium in water and air filters, which are matrices prepared in EML's QAP. The LLD for americium calculated using the approach described in the EML Procedures Manual (Chieco et al., 1992) (assuming the counter efficiency of $\sim 30 \%$, the detector background in the region of interest (ROI) for americium of $1.6 \times 10^{-5}$ counts $\mathrm{sec}^{-1}$, and the expected chemical recovery of $80 \%$ ) is equal to $0.1 \mathrm{mBq}$ for a $5000 \mathrm{~min}$ count. Real aqueous samples, such as sea water, might behave somewhat differently due to a higher concentration of inorganic ions. Because this method represents tremendous savings both in time needed as well as in waste generated, it should be tested on as broad a range of real samples as possible. 


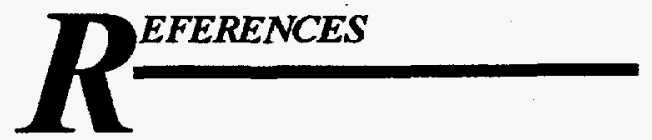

Chieco, N. A., D. C. Bogen, and E.O. Knutson (Editors)

"EML Procedures Manual"

USDOE Report HASL-300, 27th Edition, November (1992)

Horwitz, E. P., M. L. Dietz, D. M. Nelson, J. J. LaRosa, and W. D. Fairman,

"Concentration and Separation of Actinides from Urine Using a Supported Bifunctional

Organophosphorus Extractant".

Anal. Chim. Acta, 238, 263271 (1990)

Nelson, D. M. and W. D. Fairman

"Application of a Novel Method for Measuring Actinide Elements in Urine"

Presented at the 36th Annual Conference on Bioassay, Analytical and Environmental Radiochemistry,

Oak Ridge, Tennessee (1990)

Milyukova, M. S., N. I. Gusev, I. G. Sentyurin, and I. S. Sklyarenko

"Analytical Chemistry of Plutonium"

Ann Arbor-Humphrey Science Publishers, Ann Arbor - London (1969)

O'Malley, B.

"USDOE Procedures Database".

Los Alamos National Laboratory (1994)

Sanderson, C. G.

"Semi-Annual Report of the Department of Energy, Office of Environmental Restoration and Waste Management, Quality Assessment Program"

USDOE Report EML-569, July (1995) 


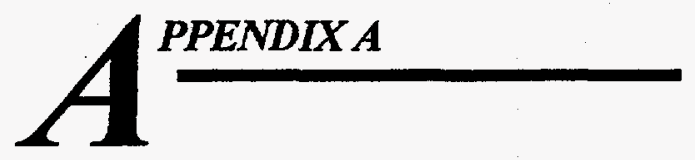

Am-04

AMERICIUM IN QAP WATER AND AIR FILTERS - EICHROM'S TRU RESIN

\begin{abstract}
APPLICATION
The following procedure has been applied to the preparation, separation, and analysis of spiked water and air filter samples that contain americium but not lanthanides (Berne, 1995). Lanthanides, if present, will not be removed by this method and will significantly reduce the resolution of the $\alpha$-spectrograph. Combined with Procedure Pu- $11,{ }^{*}$ this procedure allows for the sequential determination of plutonium and americium. Other researchers have applied TRU Resin methods to other matrices (Horowitz et al., 1990). The procedure is used in the EML Quality Assessment Program (QAP) (Sanderson et al., 1995).

The water and air filters are equilibrated with ${ }^{243} \mathrm{Am}$ and processed through the plutonium separation steps using ion exchange resin according to Procedure $\mathrm{Pu}-11$.* If determination of plutonium is desired, an appropriate plutonium tracer should be added along with the ${ }^{243} \mathrm{Am}$ tracer. The eluate from the ion exchange column containing americium (and all other ions, except plutonium) is evaporated, redissolved, and loaded onto a TRU Resin extraction column. The americium (and curium, if present) is separated and purified on the column and finally stripped with dilute nitric acid stripping solution. Microprecipitation is used to prepare for $\alpha$ spectrometry.
\end{abstract}

\title{
SPECIAL REAGENTS
}

1. EICHROM'S TRU Resin, ion extraction resin, particle size 100-150 $\mu \mathrm{m}$, Eichrom Industries, Inc., Darien, IL 60561.

2. Column feed solution, $0.5 \mathrm{M} \mathrm{Al}\left(\mathrm{NO}_{3}\right)_{3}$ in $2 \mathrm{M} \mathrm{HNO}_{3}$ - place $18.76 \mathrm{~g}$ of $\mathrm{Al}\left(\mathrm{NO}_{3}\right)_{3} \cdot 9 \mathrm{H}_{2} \mathrm{O}$ in a $100-\mathrm{mL}$ volumetric flask and add $2 \mathrm{M} \mathrm{HNO}_{3}$ to the mark. Shake to mix thoroughly.

3. $2 \mathrm{M} \mathrm{HNO}_{3}-125 \mathrm{~mL} \mathrm{HNO}_{3}$ diluted to $1 \mathrm{~L}$ with $\mathrm{H}_{2} \mathrm{O}$.

4. $1 \mathrm{M} \mathrm{HNO} \mathrm{HN}_{3}-62.5 \mathrm{~mL} \mathrm{HNO}_{3}$ diluted to $1 \mathrm{~L}$ with $\mathrm{H}_{2} \mathrm{O}$.

5. $0.025 \mathrm{M} \mathrm{HNO}_{3}-25 \mathrm{~mL} 1 \mathrm{M} \mathrm{HNO}$ diluted to $1 \mathrm{~L}$ with $\mathrm{H}_{2} \mathrm{O}$.

6. Eichrom's TRU Resin column or equivalent $-2 \mathrm{~mL}$ columns from Eichrom Industries or can be prepared from TRU Resin. Place a plug of glass wool in the bottom of polyethylene transfer pipette such as a $3.2 \mathrm{~mL}$ bulb draw transfer pipette ((Cat. No. 224, manufactured by Saint - Amand Mfg. Co., Inc. (SAMCO ${ }^{\$}$ ) San Fernando, CA 91340 U.S.A.)). Add slurried TRU Resin (0.5 g). Assemble immediately before use.

* EML Procedures Manual, HASL-300, 27th Edition, February (1992) 


\section{DETERMINATION}

See Plutonium Purification - Ion Exchange Technique, Procedure Plutonium-11.*

\section{ION EXTRACTION SEPARATION}

1. Collect the sample and the wash effluent from Step 4, Ion Exchange Separation, Procedure $\mathrm{Pu}-11,{ }^{*}$ and evaporate almost to dryness. If necessary, sometime during the evaporation process transfer the solution to a smaller beaker. The final residue should be contained in a beaker not larger than $50 \mathrm{~mL}$. Add $3 \mathrm{~mL}$ of $0.5 \mathrm{M} \mathrm{Al}\left(\mathrm{NO}_{3}\right)_{3}$ in $2 \mathrm{M} \mathrm{HNO}_{3}$ to each residue and heat very gently to dissolve.

2. Prepare ion extraction column.

3. Wash the resin with $15 \mathrm{~mL}$ of $2 \mathrm{M} \mathrm{HNO}_{3}$, and discard the effluent.

4. Load the column with the sample solution from Step 1. Wash the beaker with $3 \mathrm{~mL}$ of column-feed solution and add to the column. Discard the effluent.

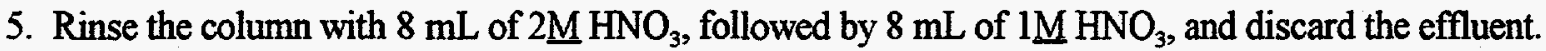

6. Elute the americium fraction with three 3-mL aliquots of $0.025 \mathrm{M} \mathrm{HNO}$ and collect the eluate in a 50$\mathrm{mL}$ beaker.

7. Evaporate the eluate to dryness. Convert the residue to the chloride form by adding $5 \mathrm{~mL}$ of $\mathrm{HCl}$ three times and evaporating to dryness at a low temperature.

8. Prepare the sample for $\alpha$ spectrometry by microprecipitation (see Procedure G-03).*

\section{DATA PROCESSING AND ANALYSIS}

For $\alpha$ spectrometry, see Alpha Radioassay, Procedure 4.5.2.1.* 


\section{LOWER LIMTT OF DETECTION (LLD) ${ }^{+}$}

The LLD is calculated according to procedures found in the EML Procedure Manual, Section 4.5.3.2.*

\begin{tabular}{ccc}
\hline Counter Efficiency & $(\%)$ & 30 \\
Counter Background & $(\mathrm{cps})$ & $1.6 \times 10^{-5}$ \\
Recovery & $(\%)$ & 80 \\
Blank & $(\mathrm{cps})$ & - \\
LLD $(400 \mathrm{~min})$ & $(\mathrm{mBq})$ & 0.5 \\
LLD $(1000 \mathrm{~min})$ & $(\mathrm{mBq})$ & 0.3 \\
LLD $(5000 \mathrm{~min})$ & $(\mathrm{mBq})$ & 0.1 \\
\hline
\end{tabular}

+ Reagent blanks must be analyzed with each set of samples.

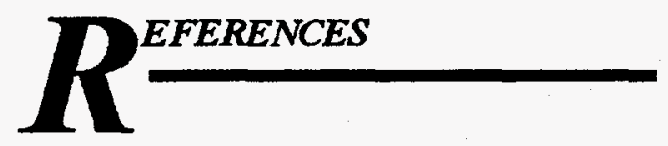

Berne, A.

"Use of EIChrom's TRU Resin in the Determination of Americium, Plutonium and Uranium in Air Filter and Water Samples"

USDOE Report EML-575, December (1995)

Sanderson, C. G., V. Pan, and P. Greenlaw

"Semi-Annual Report of the Department of Energy, Office of Environmental Restoration and Waste Management, Quality Assessment Program"

USDOE Report EML-569, July (1995) 


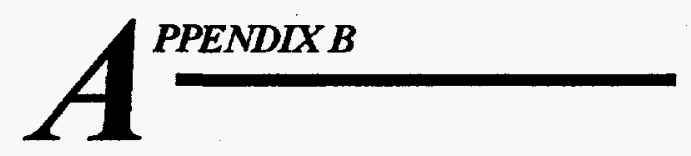

ADAPTATION OF THE Am-01 PROCEDURE* TO WATER AND AIR FILTERS

\begin{abstract}
APPLICATION
This procedure is applicable to water and air filters.

Americium and plutonium tracers are added to the sample and a procedure for plutonium, appropriate to the matrix, is followed. The last step in each procedure will be the ion-exchange technique for the purification of plutonium (see Procedure Pu-11).* The eluate from Step 4 is combined with the eluate from Step 8. Americium is coprecipitated with calcium oxalate, followed by coprecipitation with iron hydroxide. The acidified iron hydroxide solution is loaded onto an ion-exchange column to assure a complete removal of any traces of plutonium, followed by another ion-exchange column designed to remove iron. The eluate from the last column is evaporated, converted to $\mathrm{HCl}$ and microprecipitated on $\mathrm{NDF}_{3}$ and the ${ }^{241} \mathrm{Am}$ plus the ${ }^{243} \mathrm{Am}$ tracer are resolved by $\alpha$ spectrometry.
\end{abstract}

\title{
SPECIAL APPARATUS
}

1. Ion-exchange columns - see Specification 7.5.*

\section{SPECIAL REAGENTS}

1. ${ }^{243} \mathrm{Am}$ tracer solution, about $0.20 \mathrm{~Bq} \mathrm{~g}^{-1}$, in a dispensing bottle.

2. Bio-Rad AG 1-X4 resin (100-200 mesh) - see Specification 7.4.*

3. Bio-Rad AG 1-X8 resin (50-100 mesh) - see Specification 7.4.*

4. Calcium carrier solution, $100 \mathrm{mg} \mathrm{Ca} \mathrm{mL}^{-1}$ - dissolve $25 \mathrm{~g} \mathrm{CaCO}_{3}$ in a minimum of $\mathrm{HNO}_{3}$ and dilute to $100 \mathrm{~mL}$.

5. Iron carrier solution, $100 \mathrm{mg} \mathrm{Fe} \mathrm{mL}^{-1}$ - slowly heat $100 \mathrm{~g}$ of iron powder in $500 \mathrm{~mL} \mathrm{HCl}$ until reaction ceases. Carefully and slowly add $100 \mathrm{~mL} \mathrm{HNO}_{3}$ while stirring. Cool and dilute to $1 \mathrm{~L}$.

6. Oxalate wash solution - dissolve $10 \mathrm{~g}$ of oxalic acid $\left(\mathrm{H}_{2} \mathrm{C}_{2} \mathrm{O}_{4} \cdot 2 \mathrm{H}_{2} \mathrm{O}\right)$ to make $1 \mathrm{~L}$ of solution $(\sim 1 \%$ solution). 


\section{PROCEDURE}

1. Combine eluates from Steps 4 and 8 from Plutonium-11* in a beaker. Evaporate to dryness. Dissolve the residue in $5 \mathrm{~mL} \mathrm{7.5 \textrm {M } \mathrm { HNO }}{ }_{3}$, add $45 \mathrm{~mL} \mathrm{H}_{2} \mathrm{O}$ and stir.

2. Add $1 \mathrm{~mL}$ of Ca carrier solution (100 mg Ca) and $2.5 \mathrm{~g}\left(50 \mathrm{~g} \mathrm{~L}^{-1}\right)$ oxalic acid to the sample while stirring with a magnetic stirrer.

3. Adjust the $\mathrm{pH}$ of the solution to $2.5-3.5$ with $\mathrm{NH}_{4} \mathrm{OH}$ using $\mathrm{pH}$ paper as an indicator and continue to stir for $30 \mathrm{~min}$. Remove magnetic stirrer.

4. Cool and let stand overnight or for more than $6 \mathrm{~h}$. Check for completeness of precipitation using a drop of saturated oxalic acid solution.

5. Aspirate (or decant) as much liquid as possible without disturbing the precipitate. Transfer precipitate to a $250-\mathrm{mL}$ centrifuge bottle using oxalate wash solution. Balance the bottles on a double pan balance and centrifuge for $10 \mathrm{~min}$ at $2000 \mathrm{rpm}$. Decant and discard the supernate.

6. Break up the precipitate with a stirring rod and wash the precipitate with the oxalate wash solution. Centrifuge, decant and discard the wash. Repeat wash. Redissolve the precipitate in a minimal amount of $\mathrm{HNO}_{3}$ and transfer the solution quantitatively to a beaker. Heat to destroy the oxalate ion.

7. Dissolve the wet-ashed residue in $5 \mathrm{~mL}$ of $7.5 \mathrm{M} \mathrm{HNO}_{3}$ and transfer to a $40-\mathrm{mL}$ centrifuge tube, using $\mathrm{H}_{2} \mathrm{O}$ to complete transfer and dilute to $25 \mathrm{~mL}$ of solution. Warm the solution in a $90^{\circ}$ hot water bath and add $0.1 \mathrm{~mL}$ iron carrier solution (10 $\mathrm{mg} \mathrm{Fe})$.

8. With the centrifuge tube in the hot water bath adjacent to a hood, adjust the $\mathrm{pH}$ of the solution to 8-9 with $\mathrm{NH}_{4} \mathrm{OH}$ while stirring with a glass rod. Allow solution to digest in hot water bath for $20 \mathrm{~min}$.

9. Cool in a cold water bath, rinse and remove the glass rod. Centrifuge for $10 \mathrm{~min}$ at $2000 \mathrm{rpm}$.

10. Decant (or aspirate) and discard the supernate. Add 5 drops $\mathrm{HCl}$ to dissolve the $\mathrm{Fe}(\mathrm{OH})_{3}$ pellet followed by $25 \mathrm{~mL} \mathrm{H}_{2} \mathrm{O}$. Heat the solution in a hot water bath.

11. Repeat Steps 8,9 and 10 three times. Redissolve the final precipitate in $7.5 \mathrm{M} \mathrm{HNO}_{3}$.

12. Transfer to a $250-\mathrm{mL}$ beaker, evaporate to dryness, add $20 \mathrm{~mL} 7.5 \mathrm{M} \mathrm{HNO}_{3}$ and evaporate to dryness again.

13. Dissolve the dry residue immediately in $40 \mathrm{~mL} 7.5 \mathrm{M} \mathrm{HNO}_{3}$. Cool in an ice-water bath. Add $0.6-1.0 \mathrm{~g} \mathrm{NH}_{2} \mathrm{OH} \cdot \mathrm{HCl}$, dissolve and let react for $15 \mathrm{~min}$. Heat on low temperature hot plate to decompose unreacted $\mathrm{NH}_{2} \mathrm{OH} \cdot \mathrm{HCl}$, then bring to gentle boil for 1-2 min. Cool and pass the solution through a 7.5 $\mathrm{M} \mathrm{HNO}_{3}$ ion-exchange column (see Note 1). Adjust the rate of elution to $\sim 0.5 \mathrm{~mL}$ $\mathrm{min}^{-1}$. Collect the effluent in a $400-\mathrm{mL}$ beaker. Wash with $150 \mathrm{~mL} 7.5 \mathrm{M} \mathrm{HNO}$ and collect the effluent in the $400-\mathrm{mL}$ beaker.

14. Evaporate the sample to dryness and treat several times with small volumes of $\mathrm{HCl}$. Dissolve the final residue in $30 \mathrm{~mL}$ of $\mathrm{HCl}$. Pass this solution through a $12 \mathrm{M} \mathrm{HCl}$ ion-exchange column (see Note 2). Collect the effluent in a $250-\mathrm{mL}$ beaker. Wash with $100 \mathrm{~mL}$ of $\mathrm{HCl}$, and collect in the $250-\mathrm{mL}$ beaker.

15. Evaporate to dryness. Dissolve the residue in $1-2 \mathrm{~mL} 1 \mathrm{M} \mathrm{HCl}$. 
16. See Procedure G-03* for microprecipitation source preparation for $\alpha$ spectrometry.

17. Submit the sample for $\alpha$ spectrometry measurement.

Notes:

1. Preparation of $7.5 \mathrm{MHNO}_{3}$ Column. Position a plug of glass wool at the base of a small column (i.d. $11 \mathrm{~mm}$ ). Transfer $10 \mathrm{~mL}$ of wet séttled Bio-Rad AG-X8 resin (50-100 mesh) to the column and allow it to settle. Place a second plug of glass wool on top of the resin, and with the stopcock open allow the $\mathrm{H}_{2} \mathrm{O}$ to reach the level of the upper plug. Wash the column with $40 \mathrm{~mL}$ of $\mathrm{H}_{2} \mathrm{O}$, followed by 300 $\mathrm{mL}$ of 7.5 $\mathrm{M} \mathrm{HNO}_{3}$, passed through the resin bed in $50-\mathrm{mL}$ portions. Allow the level of each portion to reach the top of the upper plug. The conversion of the resin is complete if the effluent from the column tests negative for $\mathrm{Cl}^{-}$using a dilute silver nitrate solution.

2. Preparation of $\mathrm{HClColumn}$. Position a plug of glass wool at the base of a small column (i.d. $11 \mathrm{~mm}$ ). Transfer $10 \mathrm{~mL}$ of wet settled Bio-Rad AG-X4 resin (100-200 mesh) to the column and allow it to settle. Place a second plug of glass wool on top of the resin, and with the stopcock open allow the $\mathrm{H}_{2} \mathrm{O}$ level to reach the level of the upper plug. Pass two 50-mL volumes of $\mathrm{HCl}$ through the resin bed and allow each to reach the top of the upper glass plug. Make sure to run this column in a vented hood.

\section{DATA PROCESSING AND ANALYSIS}

For $\alpha$ spectrometry measurements, see Procedure 4.5.2.* 



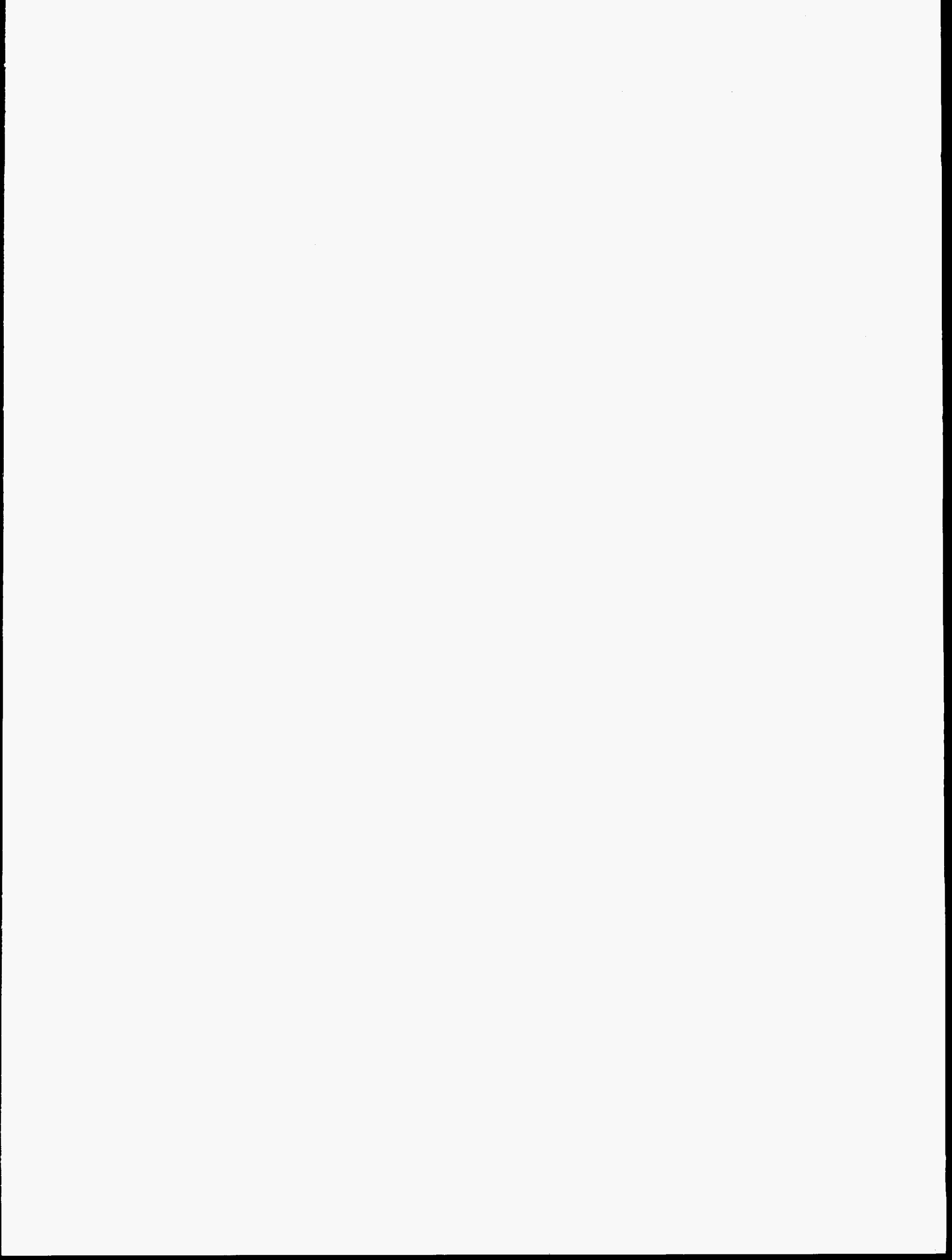




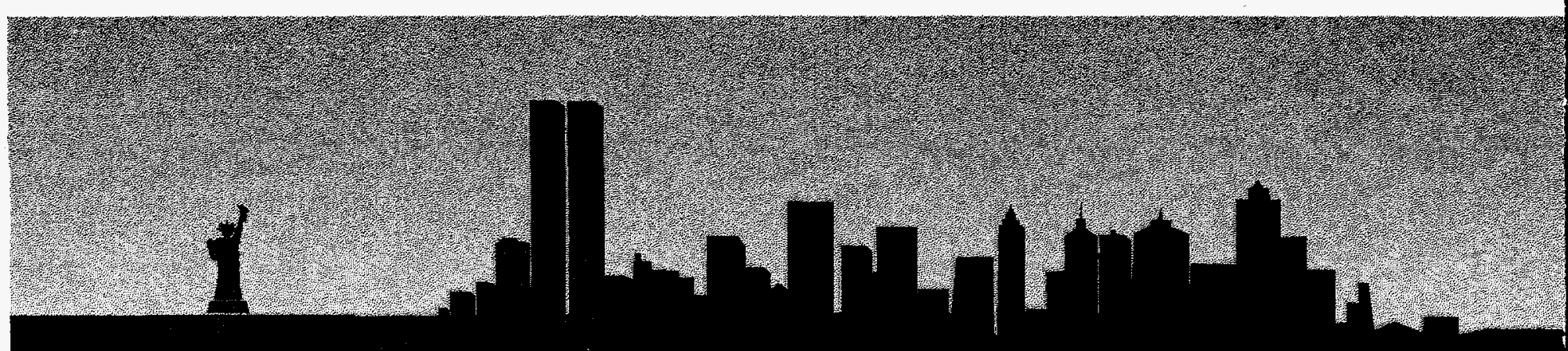

